\title{
Cenários e práticas comunicacionais emergentes na América Latina: reflexões sobre culturas juvenis, mídia e consumo
}

\section{Rose de Melo Rocha}

Doutora em Ciências da Comunicação pela ECA-USP, com pós-doutorado em Ciências Sociais pela PUC-SP. É coordenadora adjunta do PPGCOM-ESPM e Coordenadora do NP Comunicação e Culturas Urbanas da Intercom

RESUMO: Objetiva-se neste artigo analisar cenários e práticas comunicacionais emergentes protagonizadas por setores juvenis latino-americanos, com ênfase no contexto brasileiro. Tomando por inspiração cenas do filme “Apenas o fim” (2009), do carioca Matheus Souza, coloca-se em discussão determinadas práticas comunicacionais juvenis nas quais narrativas midiáticas são apropriadas, revelando subjetividades e epistemes particulares.

PALAVRAS-CHAVE: comunicação; consumo; culturas juvenis; narrativas midiáticas

\section{Prólogo: comunicação, consumo e expressividades juvenis}

Com o objetivo de refletir sobre cenários comunicacionais emergentes, este artigo se vale de resultados advindos de projeto de pesquisa desenvolvido por sua autora junto ao Mestrado em Comunicação e Práticas de Consumo da Escola Superior de Propaganda e Marketing, sediado na cidade de São Paulo, Brasil. Neste estudo os processos midiáticos contemporâneos são percebidos a partir de dois contextos reflexivos convergentes: as políticas de visibilidade e a relação entre culturas juvenis e culturas do consumo.

Em um primeiro momento, e retomando pressupostos que tem orientado minha abordagem das narratividades juvenis, gostaria de apresentar as principais bases teóricas e os princípios analíticos fundamentais que contextualizam a interpretação que irei sugerir e que sustentam minha argumentação. Eles se constituem especificamente a partir de três grandes norteadores reflexivos: 1) a proposição de uma estreita articulação entre os campos da comunicação e do consumo; 2) a caracterização da comunicação como chave conceitual para, hoje, se pensar a cultura; e 3) a consideração das juventudes como sendo lócus e sinalizadoras privilegiadas para refletir-se sobre cenários e práticas comunicacionais emergentes.

O primeiro destes norteadores diz respeito à condição estruturante do consumo de materialidades e de representações midiáticas na conformação de uma ampla e complexa cultura comunicacional. Consumir, neste caso, é muito mais do que mero exercício de gostos, caprichos ou compras irrefletidas, mas todo um conjunto de processos e fenômenos socioculturais complexos, mutáveis, através dos quais se realizam a apropriação e os 
diferentes usos de produtos, serviços e, nos remetendo a Arjun Appadurai (1999: 316-7), campo social fundamental a partir do qual se legitimam poderosos "ideopanoramas".

Em sentido complementar, defende-se que o consumo da comunicação é fundamental para localizar a reflexão proposta em um campo de ação no qual a produção imaginária dá-se em interação com toda uma rede de materialidades e negociações simbólicas. Pensar no consumo e pensar o consumo implica assim investigar as possibilidades estéticas e éticas por ele engendradas. Desenvolvendo este ponto de vista, temos que

assumir uma leitura essencialmente política deste perene casamento entre comunicação e consumo (...) inevitavelmente significa falar em mídia. Significa, ademais, defender uma concepção de mídia associada à percepção de seu inegável espraiamento social, seja enquanto prática concreta, seja como mecanismo simbólico, seja como sistema-mundo capaz de oferecer lógicas mediadas de percepção e ação cultural (Rocha, 2008: 37).

A dimensão política da comunicação e do consumo que está sendo proposta não se vincula a uma postura ou à adesão a um projeto ideológico tradicional. Antes, interessa-nos exatamente auscultar a relação entre comunicação, consumo e politicidades emergentes percebendo a "tessitura comunicacional do social” (MartínBarbero, 2000: 36). Para o autor, referência sempre renovada para o estudo da comunicação em contextos iberoamericanos, a comunicação deve ser percebida como uma questão de cultura, ou de culturas, e não apenas de ideologias. Em sentido complementar, falar de comunicação não comportaria uma reflexão que se restringisse aos aparatos e estruturas, mas demandaria análises que se refiram a sujeitos e atores sociais.

Para a investigadora colombiana Ana María Lalinde, este é, ainda, um possível norteador para estruturarmos, inclusive metodologicamente, nossos cursos e programas de pesquisa em comunicação. Segundo afirma, a proposta de Martín-Barbero
(...) não se refere à superação dos problemas de legitimação teórica do campo da comunicação, mas se dirige a um objetivo mais ambicioso: o de sua legitimação intelectual, quer dizer, à compreensão da comunicação como lugar estratégico desde o qual pensar a sociedade, e à constituição do comunicador como intelectual (Lalinde, 1998: 129; tradução e grifos nossos).

Por outro lado, se nos referirmos à produção da comunicação em um sentido mais amplo, que ultrapassa condicionantes estritamente produtivos, podemos insistir, contando ainda com os aportes barberianos, que, neste aspecto, não se trataria apenas de identificar dinâmicas de reprodução (de formas, conteúdos e imaginários midiáticos), mas, fundamentalmente, de localizar os usos sociais dos meios, as recriações de seus conteúdos e a criação de novos significantes e significados.

Falar em culturas midiáticas equivale, portanto, a localizar a centralidade e o espraiamento da lógica midiática na efetiva estruturação das localidades, seja em termos de sua materialidade, seja em suas dimensões simbólicas. Esta lógica e estas dinâmicas penetraram em macro-contextos sociais. A sociedade se midiatizou. 
A comunicação contemporânea faz visibilidade e exige visibilidade, e, exatamente por isto, é nela e com ela que se articulam novas politicidades e potencialidades expressivas.

Examinando as reflexões de Mauro Cerbino, investigador italiano radicado na Venezuela, percebemos as politicidades como um "quê-fazer" que provêm da vida cotidiana, das práticas estratégicas de vinculação e participação. Segundo nos explica Cerbino, “o corpo é elemento mediador e lugar de enunciação de uma nova politicidade, de um modo de ocupar e dar sentido ao espaço público e de construir uma cidadania cultural mais além da de direito" (Cerbino, 2002; tradução nossa).

Assim, e como nosso segundo argumento, propõe-se conceber a comunicação como processo. Se este processo, em si, hoje constitui o lugar expressivo primordial, ele se efetiva nas particularidades e nas variadas e conflituosas interações produzidas entre o campo da produção e o campo da recepção.

Esta natureza comunicacional fica ainda mais evidente quando sua localização prioritária dá-se junto a segmentos juvenis. Seguindo as proposições de Cerbino, temos que

[n]os usos dos estilos e das modas, em grande medida veiculadas pelas indústrias culturais, se observa a colocação em cena de processos de constituição de um complexo conjunto de significações e representações simbólicas, de tal forma que é possível afirmar que alguns grupos juvenis souberam criar sabiamente um "jogo de aparências" (Cerbino, 2005: 118; tradução nossa).

A argentina Beatriz Sarlo já havia oportunamente observado que "a juventude não é uma idade, e sim uma estética da vida cotidiana" (Sarlo, 1997: 36). A mexicana Rossana Reguillo (2000) oferece um interessante adensamento desta proposição, ao postular que, em suas investigações sobre práticas e dinâmicas de consumo cultural capitaneadas por agrupamentos e coletivos juvenis, percebe claramente a constituição das e dos jovens como sujeitos, sujeitos de discurso e sujeitos de ação:

Los jóvenes van a ser pensados como un sujeto con competencias para referirse en actitud
objetivante a las entidades del mundo, es decir, como sujetos de discurso, y con capacidad para
apropiarse (y movilizar) los objetos tanto sociales y simbólicos como materiales, es decir, como
agente sociales. En otras palabras, se reconoce el papel activo de los jóvenes en su capacidad de
negociación con las instituciones y estructuras. En este tipo de acercamiento se opera una
distancia entre un pensamiento que "toma" el mundo social y lo registra como datum, como dato
empirico independiente del acto de conocimiento y de la ciencia que lo propicia (Bourdieu, 1995),
y un pensamiento que es capaz de hacer la critica de sus propios procedimientos (Reguillo, 2000:
36).

Desde o universo do consumo e em suas interfaces com o campo midiático se apresentam e circulam conteúdos e formas culturais que compõem a vida cotidiana de diferentes juventudes, interferindo diretamente na produção de narrativas de si e na percepção das alteridades. A cultura do consumo e as culturas midiáticas participam dos processos de sociabilização, na promoção de novas sensibilidades e também compõem táticas 
astutas de tessitura de lugares, espacialidades e temporalidades alternativas de expressão, inserção e engajamento.

Neste sentido, às lógicas excludentes sobrepõem-se táticas de inclusão que nem sempre irão caracterizar uma dinâmica de adesão irrestrita ou de caráter conformista em relação à própria cultura massiva e midiática. Carlos Perea, analisando a relação de jovens colombianos com a política tradicional e recuperando criticamente os imaginários sociais a eles associados, propõe que, juntamente ao descrédito em relação às institucionalidades, nota-se o aparecimento de novas formas de se construir identidades coletivas, a ele associadas exatamente ao plano das expressividades (Perea, 1998: 129-150; tradução nossa).

Tais táticas de subjetivação e de afirmação identitária revelam um caráter comunicacional inequívoco. Investigando as políticas da visibilidade e as lutas pela representação capitaneadas por setores juvenis, o pesquisador chileno Oscar Aguilera (2008) sugere que

\begin{abstract}
A informação e a comunicação se transformam em um novo lugar de conflito constituinte de ações coletivas, ao passar por estes ditos processos/espaços as possibilidades de disputar e mudar os códigos de leitura do social assim como insumos fundamentais para a construção de projetos políticos coletivos (...). [Em um] contexto de alta densidade informacional emergem as vinculações com as novas tecnologias, com buscar informação e difundir-la através da Internet, as páginas de contra-informação assim como a possibilidade de entender que a própria prática comunicacional se transforme em um novo modo de grupalidade (Aguilera, 2008:342; tradução e grifo nossos).
\end{abstract}

A fusão do midiático ao social também produz seus desvios, também se constitui em bordas e brechas de significação. Diferentes mídias - o corpo, a cidade, os espaços virtuais - são efetivamente suportes através dos quais circulam linguagens e se produzem sentidos disruptivos. Localizamos nesta dimensão a profusa e intensa produção de ações simbólicas de ressignificação e igualmente as numerosas intervenções de apropriação do espaço e do tempo urbanos, dos grafites aos coletivos juvenis, bem como os grupos artísticos, os movimentos culturais e micro-políticos que se utilizam dos espaços virtuais como territórios de encontro e de atuação.

A problemática e o objeto "juventude" nos parecem superlativamente adequados às reflexões comunicacionais. Afinal, pensar a juventude é pensar um objeto que é igualmente sujeito, mais fortemente ainda por assumirmos como princípio metodológico nuclear a investigação das próprias narratividades e expressividades juvenis. Como precisamente apontado por Aguilera (2008),

As novas modalidades de agrupação e participação juvenil não estão circunscritas somente a tribos urbanas, mas na verdade também se encontram presentes em termos empíricos e discursivos (sentidos da ação) em grande parte das práticas juvenis. Desde esta perspectiva, as práticas juvenis estariam constituindo sua própria episteme, seu próprio estilo de pensar (...) (Aguilera, 2008: 357; tradução e grifo nossos). 


\section{Epílogo: cenas privadas midiaticamente narradas}

Um casal de jovens, idades em torno dos 20 anos, conversa sobre suas preferências culturais. O que se assiste é a uma verdadeira esgrima discursiva em torno de seus gostos. Gostos que se discutem. Gostos que constituem uma verdadeira cartografia de consumo cultural. No consumo das narrativas sobre os bens que consomem linhas de troca afetual são tecidas, nas diferenças e nas coincidências. Eles estão, lado a lado, deitados em uma cama estreita. O quarto de dormir é o cenário do encontro. Nada mais tipicamente constituinte do que se pode costuma classificar como uma condição juvenil.

A cena é de um filme, "Apenas o fim”, atualmente em exibição nas salas brasileiras. Seu diretor, igualmente jovem, chama-se Matheus Souza, tinha 19 anos e era aluno de cinema da PUC-RJ na época das filmagens. Como o próprio diretor declarou em uma entrevista recente “[é] um filme jovem, feito por jovens, sobre um casal jovem. Mas, ao mesmo tempo, fala sobre o tema mais universal do mundo, relacionamentos. (...) E é por isso que muitos adultos saem emocionados da sessão".

Voltemos ao filme: nas mãos do menino, vemos um joystick que é compulsivamente pressionado. Nada mais paradigmático da natureza da troca que se estabelece. Como em um jogo, fragmentos discursivos vão sendo sobrepostos. Ao modo de um check-list frenético falar de si e escutar sobre o outro passa por enumerar e confrontar os filmes assistidos, os grupos musicais cultuados, os brinquedos e jogos admirados, os seriados de televisão e todas as materialidades comunicacionais que daí advém. Em um diálogo sintomático a garota questiona seu par, estupefata com o fato de ele eleger "Transformers" o melhor filme do mundo:

Ela: Como você pode dizer que prefere "Transformers" a todos os filmes do Godard juntos? Você é uma vergonha para os cinéfilos do mundo todo!

Ele: $\mathrm{O}$ que pode ser mais legal do que carros normais virando robôs de 15 metros de altura? (“Apenas o Fim"; reprodução de diálogo).

As referências à cultura de massa e, muitas vezes, a uma irônica disputa entre referências cultas e o universo pop são a tônica para que o casal de protagonistas se despeça. $O$ filme fala exatamente do fim deste relacionamento. Esta triste despedida que, metaforicamente, é uma despedida da própria adolescência:

Ele: Para as boy bands, Back Street Boys é quase um Beatles.

Ela: Não! Pergunta pra qualquer garota qual é a melhor boyband. É N'Sync. Meninos entendem de futebol, meninas, de boy band.

Ele: Duvido que você não tenha sequer cogitado ir ao show do Back Street Boys no Maracanã

Ela: $\mathrm{Eu}$ fui. E você?

Ele: Não. Eu estava naquela época de fingir que só gostava de rock inglês.

Ela: Não sei por que a gente tá junto. A gente é tão diferente. Você é tão infantil. Olha isso! Você tem um bonequinho do He-Man.

Ele: Eu sou tipo aquela vontade que dá de repente de tomar Fanta uva.

Ela: Ah, e eu sou o quê? Champanhe? 
Ele: Não. Você é o Mentos. E, só pra constar, esse daqui é o Fanático, não é o He-Man. (“Apenas o fim". Diálogos do filme).

José Fernando Serrano Amaya (2004), em um belíssimo livro sobre as concepções de vida e morte em jovens urbanos, analisaria este tipo de exercício existencial-discursivo valendo-se do conceito de "sistemas expertos", nomeação que utiliza para identificar a recorrência a aportes e ordenadores midiáticos para estruturar narrativas autobiográficas. Este conceito (originalmente elaborado por A. Giddens) é aplicado para classificar alguns "modos de conhecimento técnico que se estendem às próprias relações sociais e á intimidade, e aos quais se recorre para realizar a experiência reflexiva do eu" (Amaya, 2004: 81). Tomando esta idéia como inspiração, temos que os consumos culturais operam nas narrativas juvenis "como estes sistemas expertos aos quais se recorre não apenas para (...) fazer uma predição ou suposição, mas para representar a si mesmo e aos outros" (Amaya, 2004: 82; tradução nossa).

Desenvolvendo este ponto de vista, Serrano mostra que em processos de recepção ativa de produtos culturais constrói-se uma verdadeira rede ou estoque de representações que são utilizadas pelos jovens para dar conta, por exemplo, de sua relação com a vida e a morte:

Com freqüência nos relatos dos e das jovens ao serem questionados sobre a origem ou fonte de uma determinada idéia sobre a vida ou a morte, respondiam aludindo a tê-lo visto na televisão, escutado no rádio, lido em um jornal ou apenas porque alguém me contou, sem ser mais precisos em suas referências; as histórias de vida e morte estão repletas de tais alusões, as quais pareciam formar um repertório diverso de imagens, simbologias e significados parciais que operam ao modo de padrões de referência para explicar uma determinada situação. O cinema, a televisão e determinados livros ou idéias sobre eles - como em uma leitura de pistas - são os meios descritos com mais freqüência para aludir a esta provisão de imagens, que contudo não é igual para todos os grupos de jovens com os quais trabalhamos devido a condições mencionadas anteriormente posse diferenciada de capitais, localização nas relações de produção, acesso ao sistema educacional, ente outras (Amaya, 2004: 80; tradução nossa).

Não deixa de ser significativo o contexto que deu origem a este livro que acabamos de citar. Como descrito pelo autor, tudo começou ao fim de sua graduação, quando ele e um grupo de amigos colombianos se perguntavam cada vez mais intensamente sobre o que iriam fazer no futuro. Para Amaya, o resultado das indagações e das conversas compartilhadas com os colegas de faculdade resultou em um primeiro projeto de investigação sobre as concepções juvenis de vida e morte. Para Souza, o que se realizou foi um filme. Totalmente rodado nas dependências da Pontifícia Universidade Católica do Rio de Janeiro. Como nos conta Amaya, tudo começou com a afirmação de um de seus colegas. Quando perguntado sobre o que faria no futuro, respondeu secamente: "Para qué preocuparse si como están las cosas uno se muere en cualquier momento".

Para Souza, a sugestão é a de que o fim de um namoro deu início à concepção das filmagens. Uma crítica sobre o filme, postada na internet, assume uma entonação entre o melancólico e o blasé ao pontuar a natureza no stop desta finalização: “O fim não precisa ser aquele sofrimento de choros intermináveis e afins, tão clichê 
quando se fala do fim de um romance, mas sim a possibilidade de novos amores. É isso que a gente espera, especialmente quando é jovem como os protagonistas. Nada mais, nada menos".

“Apenas o fim" certamente coloca em questão a natureza interminável e encantatória das narrativas midiáticas, mas igualmente nos permite refletir sobre o modo como a serialização da cultura aplaca e posterga encontros mais decisivos com a angústia da finitude. Os jovens do filme falam muito, incessantemente, fazendo da palavra sua teia e, muitas vezes, tornando-se presas desta própria tessitura discursiva. Por vezes é opressora no filme a presença de inúmeros não-ditos. Fala-se muito, como se neste excesso se pudesse, enfim, bloquear a dor dos desencontros e das perdas. A exemplo dos bonequinhos da infância, que ainda vivem e se atualizam na juventude, as memórias do que foi vivido se transformam, com o perdão do trocadilho, em souvenires que supostamente se poderão manipular, como se, de fato, a vida fosse vivida como uma grande cena ou encenação do vivido.

É novamente Amaya (2004) quem nos ajuda na conclusão de nossa análise. Referindo-se a um dos jovens com os quais realizou uma entrevista em profundidade, nota que

relato feito por Jairo parece ter nos objetos de consumo cultural não apenas um elemento com o qual suportar suas idéias, mas inclusive a chave mesma de seus modos de narrar-se; suas experiências de vida se contam como se tivessem sido cenas de um filme, cheias de cores e sucessos (...); chama a atenção, ademais, o lugar dado à relação com tais objetos à maneira de marcos, vestígios na história pessoal a partir dos quais se marcam novos momentos (Amaya, 2004: 80; tradução nossa).

\section{Notas}

Texto originalmente apresentado ao XIII Encuentro Latinoamericano de Facultades de Comunicación Social (Felafacs). Palácio de Convenciones de La Habana, Cuba, 19 a 22 de outubro de 2009.

\section{Referências bibliográficas}

AGUILERA, Oscar. Movidas, movilizaciones y movimientos. Cultura política y políticas de las culturas juveniles en el Chile de hoy. Universitat Autònoma de Barcelona. Departament d'Antropologia Social i Prehistòria. Tesis de Doctorado. Espanha, 2008.

AMAYA, José Fernando Serrano. Menos querer más de la vida. Concepciones de vida y muerte en jóvenes urbanos. Bogotá: DIUC y Siglo del Hombre Editores, 2004.

CERBINO, Mauro. “Movimientos y máquinas de guerra juveniles”. In: Nómadas. Bogotá, 2005, pp. 112-121. LALINDE, Ana María. “La legitimidad del campo intelectual de la comunicación”. In: Mapas nocturnos.

Diálogos com La obra de Jesús Martín-Barbero. Bogotá: Universidad Central/DIUC, 1998.

MARTÍN-BARBERO, Jesús. "La comunicación: un campo de problemas a pensar”. In: Pretextos: Conversaciones sobre la comunicación y sus contextos. Cali: Centro Editorial Universidad del Valle, 1995, pp. 150 e ss. 
. Ofício de cartógrafo. São Paulo: Loyola, 2004.

PEREA, Carlos "Somos expresión, no subversión”. In: CUBIDES, H. J.; TOSCANO, M. C. L.; VALDERRAMA, C. E. H. (orgs.). Viviendo a toda: jóvenes, territorios culturales y nuevas sensibilidades. Bogotá: Siglo del Hombre/DIUC, 1998, pp. 129-150.

REGUILLO, Rossana. "Rompecabezas de uma escritura. Jesús Martín-Barbero y La cultura em América Latina”. In: Mapas nocturnos. Diálogos com La obra de Jesús Martín-Barbero. Bogotá: Universidad Central/DIUC, 1998, pp. 79-90.

. Emergencia de culturas juveniles: estrategias del desencanto. México: Editorial Norma, 2000.

ROCHA, Rose de Melo. "Comunicação e consumo. Por uma leitura política dos modos de consumir”. In: BACCEGA, Maria Aparecida (org.). Comunicação e culturas do consumo. São Paulo: Atlas, 2008, pp. 119131.

. “A cartola da mídia. Sacando imagens, materializando magias”. In: Revista Famecos. Porto Alegre: Famecos/Sulinas, 2004.

SARLO, Beatriz. Cenas da vida pós-moderna. Rio de Janeiro: Ed. UFRJ, 1997. 